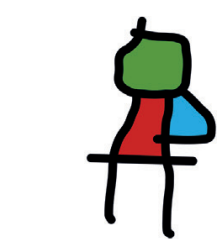

SEICAIP

\section{Allergologia et immunopathologia}

Sociedad Española de Inmunología Clínica, Alergología y Asma Pediátrica

www.all-imm.com

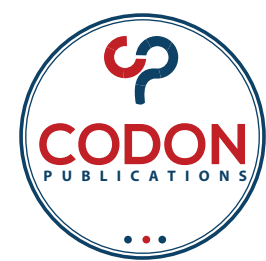

ORIGINAL ARTICLE

OPEN ACCESS (C)(1)(2)

\title{
The comparison of physical fitness and anaerobic capacity in asthmatic and non-asthmatic children
}

\author{
Asli Papurcua ${ }^{a *}$ Sema Savci ${ }^{b}$, Buse Ozcan Kahraman ${ }^{b}$, Aylin Tanriverdia, Gizem Atakulc, \\ Egemen Manci ${ }^{\text {d, Serap Acar }}{ }^{\mathrm{b}}$, Suna Asilsoyc ${ }^{c}$ Ozkan Karaman ${ }^{c}$, Nevin Uzuner ${ }^{c}$
}

\author{
${ }^{a}$ Graduate School of Health Sciences, Dokuz Eylul University, Izmir, Turkey \\ ${ }^{b}$ School of Physical Therapy and Rehabilitation, Dokuz Eylul University, Izmir, Turkey \\ 'Department of Child Health and Diseases, Division of Child Immunology and Allergic Diseases, Faculty of Medicine, \\ Dokuz Eylul University, Izmir, Turkey \\ ${ }^{d}$ Graduate School of Health Sciences, Department of Physical Education and Sports, Dokuz Eylul University, Izmir, Turkey
}

Received 2 March 2020; Accepted 15 December 2020

Available online 1 May 2021

\section{KEYWORDS \\ anaerobic capacity; asthma; \\ physical fitness test \\ battery; \\ tri-axial \\ accelerometer}

\begin{abstract}
Introduction and objective: Asthma, is the most common chronic inflammatory disease in childhood period. It can affect the daily life to an advanced level and may become vital. The purpose of this study is to compare physical fitness and anaerobic capacity in asthmatic children (AC) and non-asthmatic children (NC).

Materials and methods: A total of 47 children participated in the study; 25 individuals with mild to moderate asthma and 22 healthy children were assessed. The assessed variables consist pulmonary function and peripheral muscle strength (PMS). Additionally, physical fitness was evaluated by using fitnessgram test battery, which includes body composition, modified shuttle walk test (MSWT), curl-up test, push-up test, and sit and reach test variables. Anaerobic capacity was measured with wingate anaerobic capacity test (WAnT) and counter-movement jump (CMJ) using a tri-axial accelerometer.

Results: $\mathrm{FEV}_{1} / \mathrm{FVC}$ ratio $(\mathrm{p}<0.01)$, MSWT $(\mathrm{p}=0.001)$, push-up test $(\mathrm{p}<0.01)$, and WAnT peak power $(p<0.05)$ were measured significantly to be found reduced in AC compared with that of NC. Between the two groups, PMS, curl-up test, sit and reach test, and CMJ were not significantly different $(p>0.05)$. High to moderate positive correlation was found among WAnT, CMJ parameters and FEV1, fat-free body mass (FFM), dominant handgrip, and quadriceps strengths $(\mathrm{p}<0.05)$.

Conclusions: Physical fitness level and anaerobic capacity were lower in AC compared with that of NC. Physical fitness parameters and anaerobic exercise capacity should be evaluated on the physiotherapy and rehabilitation program in AC.

(c) 2021 Codon Publications. Published by Codon Publications.
\end{abstract}

${ }^{*}$ Corresponding author: Asli Papurcu, School of Physical Therapy and Rehabilitation, Dokuz Eylul University, Izmir, Turkey. Email address: papurcuasli@gmail.com 


\section{Introduction}

Asthma is a chronic inflammatory disease characterized by lower airway hypersensitivity and variable airflow limitation that can be resolved spontaneously or by treatment. ${ }^{1}$ Asthma, which can affect people's daily life to an advanced level and may even become vital, is the most common disease during childhood. ${ }^{1}$

Physical fitness consisting of body composition, cardiorespiratory endurance, and musculoskeletal fitness is an important indicator of health. Different studies have reported that the prevalence of asthma may be higher in obese children..$^{2-4}$ Many studies have been reported in children with mild to moderate asthma that aerobic capacity was affected to some degree. ${ }^{5,6}$ Even though there have been many studies in the literature about obese asthmatic children $(\mathrm{AC})$, there is lack of data for the comparison of $A C$ with normal weight healthy peers especially for the physiological explanation of physical activity measurements.

Clinical asthma symptoms (wheezing, dyspnea, chest tightness, and coughing) ${ }^{1}$ cause postural deteriorations and musculoskeletal influences as a result of using the accessory respiratory muscles in the progress of the disease. ${ }^{7}$ Peripheral muscle weakness is common in patients with chronic respiratory disorders and contributes to the restriction of exercise. ${ }^{8}$ However, the results of studies on muscle strength effects in AC are contradictory. ${ }^{8,9}$

The literature studies investigating the interaction between aerobic fitness and physical activity have also reported contradictory results. ${ }^{10}$ Since aerobic capacity evaluation is based on objective clinical assessments, the previous studies assessed the physical fitness especially with questionnaires ${ }^{11,12}$; they did not measure with objective methods such as fitnessgram test battery. This has not been carried out before in AC compared with healthy peers.

Anaerobic activities are part of children's daily physical activities..$^{13}$ Therefore, the anaerobic capacity should be evaluated in conjunction with physical fitness. In the literature, the measure of anaerobic capacity consists of three methods. One of them is the test of anaerobic alactacid or phosphagen power, the second one is the wingate anaerobic test and the third one is force-velocity (FV) test. ${ }^{14,15}$ The studies that observe anaerobic capacity in asthma are controversial and inadequate in the literature..$^{16,17}$ Wingate anaerobic capacity test (WAnT) is proven to be one of the most valid and reliable test to evaluate the anaerobic capacity. ${ }^{18}$ WAnT is a requirement for motivation and the suitable bicycle with controlled laboratory conditions. Recently, the tri-axial accelerometer has been used to measure parameters such as height, take-off force, impact force, peak speed, and maximum concentric power during counter-movement jump (CMJ) test in healthy children. ${ }^{14}$ CMJ is a reliable test that detects the individual's explosive power with height. ${ }^{19}$ In addition, to the best of our knowledge, there is no study that uses the tri-axial accelerometer in CMJ on asthma patients.

Therefore we hypothesized that objectively measurement of physical fitness and measure of different types of methods to assess anaerobic capacity would be to distinguish between the $A C$ and the non-asthmatic children (NC) in terms of assessed variables. Additionally, a question arises if two different anaerobic test measures are related to each other in terms of WAnT and CMJ using a tri-axial accelerometer with physical fitness parameters.

\section{Material and Methods}

\section{Participants}

The study was conducted between July 2018 and May 2019 on 47 children which are diagnosed by Faculty of Medicine, Department of Child Health and Diseases, Unit of Child Immunology and Allergic Diseases in Dokuz Eylul University: 25 AC of 7-18 years old who did not have any orthopedic and neurologic problems, and 22 non-asthmatic children (NC) of age-matched control range. Hemodynamic instability, unconsciousness, and inadequate cooperation, and those who refused to participate in the study were excluded. NC included volunteers, non-smokers without a previous history of respiratory diseases, and orthopedic problems.

The study protocol was approved by The Noninvasive Research Ethics Board of Dokuz Eylul University under the decision number 2018/16-2 on June 28, 2018. All of the participants and their legal guardians gave written informed consent.

The sample size determination using the $G^{*}$ Power (version 3,1$)$ program was based on a handgrip parameter in a similar research. ${ }^{20}$ The analysis showed with effect size $=0.86, \alpha=0.05$, power $(1-\beta)=0.80$ that the minimum sample for the specific study was 44 participants (22 per group). ${ }^{20}$

\section{Methods}

The demographic characteristics of the participants were recorded. Childhood Asthma Control Test (CACT) was interrogated. ${ }^{1}$ Pulmonary function test (PFT) was performed in a standing position with spirometry (SensorMedics, 6200 Body Box, Viasys, USA). ${ }^{21}$ Forced Vital Capacity (FVC), Forced Expired Volume in one sec $\left(\mathrm{FEV}_{1}\right), \mathrm{FEV}_{1} / \mathrm{FVC}$, Peak Expiratory Flow (PEF), and Forced Expiratory Flow at $25-75 \%\left(F E F_{25-75 \%}\right)$ results were measured.

\section{Physical fitness assessment}

Physical fitness was evaluated with Fitnessgram Test Battery $\left(\right.$ FITNESSGRAM ${ }^{\circledR}$ ) which consists of body composition, cardiopulmonary endurance, and musculoskeletal fitness. Body composition with body analyzer (Tanita BC-418 MA, Japan ${ }^{22}$ and cardiopulmonary endurance with Modified Shuttle Walk Test (MSWT). ${ }^{23}$

MSWT, in which the speed is determined by an external "beep" sound stimulus, is based on increasing different levels of walking speed for each minute. Each shuttle is represented as a distance of 10 -meter walk distance. The test was completed on the 12th level, with increasing the number of the shuttles for each level. The total number of the shuttles was recorded in meters $(m) .{ }^{24}$ Heart rate, 
$\mathrm{SaO} 2$, and the walk distance measured as percentage sign (\%) and meters ( $\mathrm{m}$ ) were measured at the beginning and at the conclusion of the test. The test was terminated in one of the following conditions: when the participant falls during the test, missed two cones, reached the maximum heart rate, or did not have sufficient physical capacity to continue. ${ }^{23}$

Musculoskeletal fitness was evaluated by curl-up for abdominal, ${ }^{25}$ push-up for upper extremity, ${ }^{25}$ and sit and reach test ${ }^{25}$ to indicate the flexibility.

To indicate peripheral muscle strength (PMS), quadriceps muscle strength was measured with a handheld dynamometer (Lafayette Instrument Company, Lafayette, Indiana, ABD), ${ }^{26}$ handgrip strength was measured using Jamar handheld dynamometer. ${ }^{27}$ The best values getting from three repetitions for each side were recorded in kilograms.

\section{Anaerobic capacity assessment}

Anaerobic capacity was determined by using WAnT and CMJ. WAnT is a laboratory test that evaluates anaerobic performance based on 30 -sec all-out sprint on a cycle ergometer against a fixed resistance (Lode, Groningen, Holland). Resistance was set in accordance with the participant's variables. Subjects were instructed to start pedaling as fast as possible after the warm-up. ${ }^{28}$

In CMJ, the tri-axial accelerometer (BTS G-Walk S.p.A. Italy), which was with $62 \mathrm{~g}$ weight, with dimensions of $78 \times 48 \times 20 \mathrm{~mm}$, was used to measure parameters such as jump height, peak speed, impact power, take-off power, and maximum concentric power. The G-Walk is a wireless motion-sensing device connected to the L4-L5 level of the individual's waist and recorded the measurements in a computer software. The highest jump height of three maximal tests was registered for our study..$^{14,29}$

\section{Statistics}

Statistical analysis was performed using SPSS software version 22 . The data are presented as mean \pm Standard
Deviation (SD). Normal distribution was evaluated by Kolmogorov-Smirnov/Shapiro-Wilk tests. Differences between the groups were analyzed under parametric conditions using "independent samples t-test" and "chi-square test." Pearson's correlation was performed to detect variables that were highly correlated. The correlation coefficients $(r)$ between variables were classified as weak (0.26-0.49), moderate (0.50-0.69), high (0.70-0.89), and very high $(0.90-1.00) .{ }^{30} \mathrm{P}<0.05$ were regarded as statistically significant in all analyses.

\section{Results}

\section{Participants}

Table 1 depicts the demographic and clinical characteristics of the participants. According to the results from Table 1, there were no significant differences in gender, age, and body mass index (BMI) between the two groups $(p>0.05)$. Mean CACT in AC was $21.80 \pm 2.90$. $\mathrm{FEV}_{1} / \mathrm{FVC}$ was significantly lower in AC than NC $(p=0.008)$.

\section{Physical fitness}

Table 2 portrays the physical fitness findings of the participants. We can see that, body composition, curl-up test, sit and reach test, dominant handgrip, and quadriceps strength were similar in both groups $(p>0.05)$. MSWT heart rate (ending and delta) $(\mathrm{p}=0.001)$ and distance (meter and percentage) $(p=0.001)$, push-up test $(p=0.008)$ were significantly lower in AC than NC.

\section{Anaerobic capacity}

Table 3 illustrates the WAnT and CMJ findings of the participants. WAnT peak power $(\mathrm{W} / \mathrm{kg})$ was significantly lower in $A C(p=0.034)$. There were no significant differences in CMJ between the two groups $(p>0.05)$.

Table 1 Characteristics of asthmatic and non-asthmatic children.

\begin{tabular}{|c|c|c|c|c|}
\hline Variables & $A C(n=25)$ & $N C(n=22)$ & $\mathrm{t}$ & $\mathrm{p}$ \\
\hline Gender (girl/boy) & $4 / 21$ & $5 / 17$ & & 0.559 " \\
\hline Age (years) & $13.60 \pm 2.02$ & $14.04 \pm 2.38$ & 0.694 & $0.491^{\ddagger}$ \\
\hline Height (cm) & $163.22 \pm 13.18$ & $163.92 \pm 13.46$ & 0.180 & $0.858^{\ddagger}$ \\
\hline Body weight (kg) & $60.91 \pm 15.69$ & $57.67 \pm 20.59$ & -0.611 & $0.545^{\ddagger}$ \\
\hline BMI $\left(\mathrm{kg} / \mathrm{m}^{2}\right)$ & $22.56 \pm 3.82$ & $20.78 \pm 4.46$ & -1.475 & $0.147^{\ddagger}$ \\
\hline \multicolumn{5}{|c|}{ Pulmonary Function Test } \\
\hline $\mathrm{FEV}_{1}(\%)$ & $94.44 \pm 12.06$ & $100.59 \pm 10.59$ & 1.845 & $0.072^{\ddagger}$ \\
\hline FVC (\%) & $93.36 \pm 10.09$ & $95.631 \pm 3.73$ & 0.653 & $0.517^{\ddagger}$ \\
\hline $\mathrm{FEV}_{1} / \mathrm{FVC}$ & $84.52 \pm 7.53$ & $90.12 \pm 6.18$ & 2.765 & $0.008^{*}$ \\
\hline PEF (\%) & $90.24 \pm 14.36$ & $85.45 \pm 13.95$ & -1.155 & $0.254^{\ddagger}$ \\
\hline$F E F_{25-75 \%}$ & $88.12 \pm 26.87$ & $101.22 \pm 15.72$ & 2.004 & $0.051^{\ddagger}$ \\
\hline
\end{tabular}

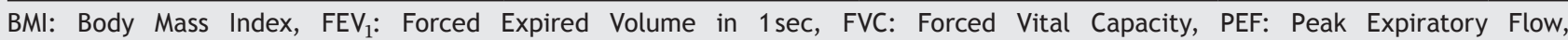
$\mathrm{FEF}_{25-75 \%}$ : Forced Expiratory Flow at 25-75\%, "Fisher chi-squire test, "Independent samples t test, * $\mathrm{p}<0.05$. 
Table 2 Physical fitness in asthmatic and non-asthmatic children.

\begin{tabular}{|c|c|c|c|c|}
\hline FITNESSGRAM $^{\circledast}$ & $A C(n=25)$ & $N C(n=22)$ & $\mathrm{t}$ & $\mathrm{p}$ \\
\hline \multicolumn{5}{|l|}{ Body composition } \\
\hline Body fat percentage & $22.19 \pm 9.93$ & $18.20 \pm 9.39$ & -1.407 & $0.166^{\ddagger}$ \\
\hline Body muscle percentage & $41.68 \pm 5.60$ & $46.31 \pm 11.32$ & 1.809 & $0.77^{\ddagger}$ \\
\hline Fat-free mass $(\mathrm{kg})$ & $46.98 \pm 11.87$ & $69.59 \pm 112.00$ & 1.005 & $0.320^{\ddagger}$ \\
\hline \multicolumn{5}{|l|}{ Modified shuttle walk test (MSWT) } \\
\hline Heart rate-before the test & $83.64 \pm 17.18$ & $86.77 \pm 12.48$ & 0.706 & $0.484^{\ddagger}$ \\
\hline Heart rate-after the test & $137.84 \pm 26.17$ & $167.27 \pm 25.77$ & 3.878 & $0.001^{* *}$ \\
\hline$\Delta$ Heart rate & $54.20 \pm 23.69$ & $80.50 \pm 24.43$ & 3.734 & $0.001^{* *}$ \\
\hline Maximum heart rate (\%) & $69 \pm 13.31$ & $84.09 \pm 13.28$ & 3.881 & $0.001^{* *}$ \\
\hline SpO2-before the test & $96.84 \pm 1.59$ & $97.13 \pm 1.28$ & 0.694 & $0.485^{\ddagger}$ \\
\hline SpO2-after the test & $96.48 \pm 1.66$ & $96.86 \pm 1.64$ & 0.794 & $0.431^{\ddagger}$ \\
\hline$\Delta \mathrm{SpO} 2$ & $-0.36 \pm 2.27$ & $-0.27 \pm 1.45$ & -0.154 & 0.878 \\
\hline General fatigue ( $M$ Borg)- before the test & $0.16 \pm 0.47$ & $0.40 \pm 1.09$ & 1.032 & $0.332^{\ddagger}$ \\
\hline General Fatigue (M Borg)- after the test & $3.78 \pm 2.42$ & $4.59 \pm 2.30$ & 1.171 & $0.248^{\ddagger}$ \\
\hline$\Delta$ General fatigue (M Borg) & $3.62 \pm 2.40$ & $4.18 \pm 2.53$ & -0.779 & 0.440 \\
\hline Leg fatigue ( $M$ Borg)- before the test & $0.32 \pm 0.74$ & $0.18 \pm 0.85$ & -0.592 & $0.557^{\ddagger}$ \\
\hline Leg fatigue ( $M$ Borg)- after the test & $3.90 \pm 1.88$ & $4.59 \pm 2.30$ & 1.149 & $0.257^{\ddagger}$ \\
\hline$\Delta$ Leg fatigue $(M$ Borg) & $3.58 \pm 2.00$ & $4.40 \pm 2.36$ & -1.300 & 0.200 \\
\hline Distance $(\mathrm{m})$ & $609.20 \pm 180.66$ & $907.72 \pm 141.25$ & 6.247 & $0.001^{* *}$ \\
\hline Distance (\%) & $57.12 \pm 15.37$ & $80.59 \pm 9.70$ & -6.156 & $0.001^{* *}$ \\
\hline Dominant quadriceps strength (kg) & $18.21 \pm 6.54$ & $20.29 \pm 4.16$ & 1.281 & $0.207^{\ddagger}$ \\
\hline Dominant handgrip strength $(\mathrm{kg})$ & $28.58 \pm 11.36$ & $27.62 \pm 12.19$ & -0.281 & $0.780^{\ddagger}$ \\
\hline Curl-up (n) & $30.16 \pm 17.99$ & $39.27 \pm 16.98$ & 1.778 & $0.082^{\ddagger}$ \\
\hline Push-up (n) & $13.20 \pm 9.20$ & $24.09 \pm 15.81$ & 2.928 & $0.008^{\ddagger}$ \\
\hline Sit-reach test $(\mathrm{cm})$ & $1.56 \pm 6.39$ & $2.90 \pm 5.71$ & 0.758 & $0.452^{\ddagger}$ \\
\hline
\end{tabular}

SpO2: Oxygen Saturation, M Borg: Modified Borg Scale, ${ }^{\ddagger}$ Independent samples t test, ${ }^{*} \mathrm{p}<0.05$.

Table 3 WAnT and CMJ in asthmatic and non-asthmatic children.

\begin{tabular}{|c|c|c|c|}
\hline Variables & $A C(n=25)$ & $N C(n=22)$ & $\mathrm{p}$ \\
\hline \multicolumn{4}{|l|}{ WAnT } \\
\hline $\begin{array}{l}\text { Peak power } \\
\text { (W) }\end{array}$ & $399.41 \pm 189.62$ & $459.90 \pm 211.08$ & $1.0350 .306^{\ddagger}$ \\
\hline $\begin{array}{l}\text { Peak power } \\
(\mathrm{W} / \mathrm{kg})\end{array}$ & $6.57 \pm 2.12$ & $7.93 \pm 2.10$ & $2.1900 .034^{\ddagger}$ \\
\hline $\begin{array}{l}\text { Mean power } \\
\text { (W) }\end{array}$ & $303.68 \pm 138.30$ & $335.24 \pm 147.67$ & $0.7560 .453^{\ddagger}$ \\
\hline $\begin{array}{l}\text { Mean power } \\
(\mathrm{W} / \mathrm{kg})\end{array}$ & $5.03 \pm 1.60$ & $5.82 \pm 1.53$ & $0.5930 .093^{\ddagger}$ \\
\hline \multicolumn{4}{|l|}{ CMJ } \\
\hline $\begin{array}{l}\text { Jump height } \\
\text { (cm) }\end{array}$ & $22.98 \pm 6.93$ & $25.03 \pm 6.83$ & $1.0160 .315^{\ddagger}$ \\
\hline $\begin{array}{l}\text { Peak speed } \\
\qquad(\mathrm{m} / \mathrm{s})\end{array}$ & $2.69 \pm 0.46$ & $2.73 \pm 0.48$ & $0.3160 .754^{\ddagger}$ \\
\hline $\begin{array}{l}\text { Take-off force } \\
\qquad(\mathrm{kN})\end{array}$ & $0.65 \pm 0.19$ & $0.73 \pm 0.31$ & $1.0110,332^{\ddagger}$ \\
\hline $\begin{array}{l}\text { Impact force } \\
(\mathrm{kN})\end{array}$ & $0.85 \pm 0.37$ & $1.00 \pm 0.44$ & $1.2210 .228^{\ddagger}$ \\
\hline $\begin{array}{l}\text { Maximum } \\
\text { concentric } \\
\text { power }(\mathrm{kW})\end{array}$ & $2.81 \pm 1.13$ & $2.73 \pm 0.96$ & $-0.2400 .811^{\ddagger}$ \\
\hline
\end{tabular}

FIndependent samples t test, ${ }^{*} \mathrm{p}<0.05$.

WAnT: Wingate anaerobic capacity test.

CMJ: Counter-movement jump.

\section{Correlations of CMJ and WAnT with physical fit- ness in asthmatic children}

Table 4 shows the relationship between physical fitness and WAnT in AC. Weak to high correlations were found among peak power (W), mean power (W), and $\mathrm{FEV}_{1} \mathrm{FFM}$, dominant handgrip, quadriceps strengths, and push-up $(p<0.05)$. Weak to high correlations were found among peak power $(\mathrm{W} / \mathrm{kg})$, mean power $(\mathrm{W} / \mathrm{kg})$, and $\mathrm{FEV}, \mathrm{FFM}$, dominant handgrip strength, and push-up $(\mathrm{p}<0.05)$.

Table 5 outlines the relationship between physical fitness and CMJ in AC. Weak to high correlations were found between jump height, peak speed, and FEV FFM, dominant handgrip strength curl-up, and push-up $(\mathrm{p}<0.05)$. Weak to moderate correlations were found among take-off power and FFM, dominant quadriceps strength $(p<0.05)$. A weak correlation was found impact power and $\mathrm{FEV}_{1}$, FFM, dominant quadriceps strength $(\mathrm{p}<0.05)$. Moderate to high correlations were found among maximum concentric power and $\mathrm{FEV}_{1}$, FFM, dominant handgrip, quadriceps strengths $(\mathrm{p}<0.05)$.

\section{Discussion}

The results show that patients with mild to moderate asthma had reduced upper extremity muscular endurance and strength compared with their healthy peers. In addition, aerobic and anaerobic capacity in those patients were 
Table 4 Correlations of physical fitness with WAnT in asthmatic children.

\begin{tabular}{|c|c|c|c|c|c|c|c|c|}
\hline \multirow[b]{4}{*}{ Correlations } & \multicolumn{8}{|c|}{ WAnT parameters } \\
\hline & \multicolumn{8}{|c|}{$A C(n=25)$} \\
\hline & \multicolumn{2}{|c|}{$\begin{array}{l}\text { Peak power } \\
\text { (W) }\end{array}$} & \multicolumn{2}{|c|}{$\begin{array}{c}\text { Peak power } \\
(\mathrm{W} / \mathrm{kg})\end{array}$} & \multicolumn{2}{|c|}{$\begin{array}{c}\text { Mean power } \\
\text { (W) }\end{array}$} & \multicolumn{2}{|c|}{$\begin{array}{l}\text { Mean power } \\
(\mathrm{W} / \mathrm{kg})\end{array}$} \\
\hline & $r$ & $\mathrm{p}$ & r & $\mathrm{p}$ & r & $\mathrm{p}$ & r & $p$ \\
\hline $\mathrm{FEV}_{1}(\mathrm{lt})$ & 0.821 & $<0.001^{*}$ & 0.611 & $0.001^{*}$ & 0.812 & $<0.001^{*}$ & 0.535 & $0.006^{*}$ \\
\hline Fat-free mass (kg) & 0.866 & $<0.001^{*}$ & 0.552 & $0.004^{*}$ & 0.845 & $<0.001^{*}$ & 0.450 & $0.024^{*}$ \\
\hline Dominant handgrip (kg) & 0.539 & $0.005^{*}$ & 0.454 & $0.023^{*}$ & 0.555 & $0.004^{*}$ & 0.434 & $0.030^{*}$ \\
\hline Dominant quadriceps (kg) & 0.632 & $0.001^{*}$ & 0.355 & 0.082 & 0.628 & $0.001^{*}$ & 0.298 & 0.148 \\
\hline MSWT distance (m) & 0.263 & 0.204 & 0.244 & 0.240 & 0.324 & 0.114 & 0.316 & 0.124 \\
\hline MSWT distance (\%) & 0.101 & 0.632 & 0.019 & 0.929 & 0.154 & 0.463 & 0.093 & 0.658 \\
\hline Curl-up (n) & 0.211 & 0.311 & 0.180 & 0.389 & 0.216 & 0.299 & 0.174 & 0.407 \\
\hline Push-up (n) & 0.404 & $0.045^{*}$ & 0.402 & $0.047^{*}$ & 0.420 & $0.037^{*}$ & 0.414 & $0.039^{*}$ \\
\hline Sit-reach test $(\mathrm{cm})$ & -0.055 & 0.792 & 0.045 & 0.830 & -0.054 & 0.799 & 0.038 & 0.859 \\
\hline
\end{tabular}

$\Phi$ Pearson correlation analysis, $r$ : Pearson correlation coefficient, ${ }^{*} \mathrm{p}<0.05$.

WAnT: Wingate anaerobic capacity test.

Table 5 Correlations of physical fitness with CMJ in asthmatic children.

\begin{tabular}{|c|c|c|c|c|c|c|c|c|c|c|}
\hline \multirow[b]{4}{*}{ Correlations } & \multicolumn{10}{|c|}{ CMJ parameters } \\
\hline & \multicolumn{10}{|c|}{$A C(n=25)$} \\
\hline & \multicolumn{2}{|c|}{$\begin{array}{l}\text { Jump height } \\
\text { (cm) }\end{array}$} & \multicolumn{2}{|c|}{$\begin{array}{l}\text { Peak speed } \\
\text { (m/sn) }\end{array}$} & \multicolumn{2}{|c|}{$\begin{array}{c}\text { Take-off power } \\
(\mathrm{kN})\end{array}$} & \multicolumn{2}{|c|}{$\begin{array}{l}\text { Impact power } \\
(\mathrm{kN})\end{array}$} & \multicolumn{2}{|c|}{$\begin{array}{c}\text { Max. concentric } \\
\text { power }(\mathrm{kW})\end{array}$} \\
\hline & $r$ & $\mathrm{p}$ & $r$ & $\mathrm{p}$ & $r$ & $\mathrm{p}$ & $r$ & $\mathrm{p}$ & $r$ & $\mathrm{p}$ \\
\hline $\mathrm{FEV}_{1}(\mathrm{lt})$ & 0.432 & $0.031^{*}$ & 0.433 & $0.031^{*}$ & 0.391 & 0.054 & 0.414 & $0.040^{*}$ & 0.641 & $<0.001^{*}$ \\
\hline Fat-free mass (kg) & 0.444 & $0.026^{*}$ & 0.596 & $0.002^{*}$ & 0.550 & $0.004^{*}$ & 0.410 & $0.042^{*}$ & 0.823 & $<0.001^{*}$ \\
\hline Dominant handgrip (kg) & 0.577 & $0.003^{*}$ & 0.705 & $<0.001^{*}$ & 0.128 & 0.541 & -0.080 & 0.703 & 0.602 & $0.001^{*}$ \\
\hline Dominant quadriceps (kg) & 0.303 & 0.141 & 0.300 & 0.145 & 0.439 & $0.028^{*}$ & 0.456 & $0.022^{*}$ & 0.643 & $0.001^{*}$ \\
\hline MSWT distance (m) & 0.382 & 0.059 & 0.394 & 0.051 & 0.122 & 0.562 & -0.190 & 0.364 & 0.316 & 0.124 \\
\hline MSWT distance (\%) & 0.099 & 0.639 & 0.187 & 0.372 & 0.102 & 0.628 & -0.155 & 0.461 & 0.211 & 0.312 \\
\hline Curl-up (n) & 0.609 & $0.001^{*}$ & 0.514 & $0.009^{*}$ & -0.004 & 0.985 & -0.108 & 0.608 & 0.275 & 0.183 \\
\hline Push-up (n) & 0.454 & $0.023^{*}$ & 0.478 & $0.016^{*}$ & 0.227 & 0.275 & 0.017 & 0.936 & 0.367 & 0.072 \\
\hline Sit-reach test $(\mathrm{cm})$ & 0.024 & 0.911 & -0.062 & 0.768 & -0.388 & 0.055 & -0.086 & 0.684 & -0.175 & 0.404 \\
\hline
\end{tabular}

$\phi$ Pearson correlation analysis, $r$ : Pearson correlation coefficient, ${ }^{*} p<0.05$.

CMJ: Counter-movement jump.

affected by asthma. To the best of our knowledge, to date this is the first study to evaluate physical fitness with a standard test battery and use a tri-axial accelerometer in CMJ in AC.

The study showed that asthma increases the risk of obesity, ${ }^{3}$ and obesity causes poor asthma control. ${ }^{2}$ Umlawska ${ }^{31}$ found that in children with asthma, mean height and the mean FFM was lower. Although there was no significant difference in body composition of both groups in our study, FFM was lower in AC. We believe that there is an interaction between FFM and exercise performance (strength and endurance capacity) because FFM is associated with muscle mass. ${ }^{32}$ Additionally, we believe a decrease in musculoskeletal mass occurs due to many factors such as hypoxemia, malnutrition, low aerobic capacity, chronic airway obstruction, and corticosteroid in patients with chronic respiratory disorder. ${ }^{33}$ With the rise of asthma, symptoms occur imbalanced, especially in the shoulder and neck muscles. ${ }^{34}$ In our study, upper extremity muscular endurance and strength were affected in AC, whereas flexibility and abdominal muscular endurance and strength were still protected, so further studies are needed in children with asthma of different severity.

In aerobic capacity, evaluation with MSWT, NC's percentage of distance was $80 \%$, while asthmatics was $57 \%$. On an average, AC walked 298 meters lesser than NC, which was significantly higher than the clinically reported minimum walk distance difference $(20-76 \mathrm{~m}) .{ }^{35}$ Reimberg et al. ${ }^{36}$ evaluated functional capacity with MSWT, and AC walked on average 160 meters less than NC; they found that the aerobic capacity in AC was lower than NC. Because MSWT is an increasing test in each minute, walk distance can be identified with the intensity of exercise and also with oxygen uptake. ${ }^{37} \mathrm{NC}$ reached $84 \%$ of maximum heart rate in MSWT, while AC completed the test on the submaximal level with $69 \%$; this condition may be due to the reduction 
of the maximum amount of oxygen depending on the natural progress of respiratory diseases. ${ }^{38}$

PMS is an important factor affecting the level of physical activity, but it has rarely been studied in children and adolescents with asthma. ${ }^{36}$ Villa et $a .^{8}$ found that there was no difference in PMS values in children with advanced asthma, whereas their quadriceps muscular endurance was lower than normal levels. PMS was preserved in our study; we may conclude that this may be due to low asthma severity and regular treatment of the children with asthma.

In addition to the contribution of aerobic exercise to total energy production, anaerobic exercise is a part of our daily life activities. ${ }^{39}$ In a study of children with mild to moderate asthma, they proved that asthma caused anaerobic limitations, and anaerobic metabolism caused low physical fitness. ${ }^{40}$ We found that in WAnT to indicate the anaerobic capacity assessment for peak power values, it was found that significantly lower in $A C$ and mean power values were similar in the two groups. Counil et al. ${ }^{16}$ found that the maximum power outputs of children with asthma during WAnT were less, and the mean power and fatigue were the same as the control group. Counil et al. ${ }^{39}$ in another study showed that the supramaximal power outputs generally decreased regardless of exercise type in children with mild to moderate asthma. As it is known, anaerobic capacity in asthma has been studied very few, and the reasons for reducing anaerobic capacity are not entirely known. ${ }^{40}$ As a result of our findings, we can say that anaerobic capacity can be maintained and improved in $A C$, but the maximum speed at which energy is produced and mechanical efficiency may be different compared with their healthy peers.

Additionally, we assessed CMJ with a tri-axial accelerometer for anaerobic exercise capacity evaluation. WAnT and CMJ in AC had similar positive moderate-high correlations in terms of $\mathrm{FEV}_{1}$, FFM, dominant handgrip, and quadriceps muscle strength. Because of difficult conditions such as an exercise laboratory needs, and the high cost in WAnT, an easily accessible and applicable method is needed. As a result of our findings, we recommend that the use of CMJ with a tri-axial accelerometer should be investigated in further anaerobic capacity studies. Also, due to the lack of reference values, the interpretation of the test was incomplete in our study. We believe that our study will be a pioneer in future studies to cover this deficiency in the literature, and we provide a source for the usability of this device.

Klijn et al. ${ }^{40}$ showed that FFM and pulmonary functions were important determinants for anaerobic exercise performance in children with cystic fibrosis. Boas et al. ${ }^{41}$ found that anaerobic power decreased as FFM decreased in children with asthma and cystic fibrosis. We found that anaerobic capacity correlated with $\mathrm{FEV}_{1}$, FFM, PMS, and abdominal and upper extremity muscular endurance and strength. However, there is no study investigating this relationship in AC in the literature. We believe this is a topic for further research.

In this study, the number of asthmatic boys was predominant due to the higher prevalence of male gender in the age group we selected, which may be restrictive in adapting the study to the literature. Moreover, the lack of reference values in CMJ limits our study.

\section{Conclusion}

To conclude, respiratory functions, aerobic and anaerobic exercise capacity, upper extremity muscular endurance and strength in $A C$ were found lower than in their healthy peers. This study is the first study using the physical fitness test battery and tri-axial accelerometer in asthma patients; therefore, we believe that our study will be guiding for further studies on clinical practice.

We believe that physical fitness parameters and also anaerobic exercise capacity should be evaluated on the physiotherapy and rehabilitation program in AC.

\section{References}

1. Bateman ED, Hurd SS, Barnes PJ, Bousquet J, Drazen JM, FitzGerald $M$, et al. Global strategy for asthma management and prevention: GINA executive summary. Eur Respir J. 2008;31(1):143-78. https://doi.org/10.1183/09031936.00138707

2. Lang JE, Bunnell HT, Lima JJ, Hossain J, Wysocki T, Bacharier L, et al. Effects of age, sex, race/ethnicity, and allergy status in obesity-related pediatric asthma. Pediatr Pulmonol. 2019;54:1684-93. https://doi.org/10.1002/ppul.24470

3. Ahmadizar F, Vijverberg SJH, Arets HGM, de Boer A, Lang JE, Kattan $M$, et al. Childhood obesity in relation to poor asthma control and exacerbation: A meta-analysis. Eur Respir J. 2016 Oct 1;48(4):1063 LP-73. https://doi. org/10.1183/13993003.00766-2016

4. Basaran S, Guler-Uysal F, Ergen N, Seydaoglu G, BingolKarakoc G, Ufuk Altintas D. Effects of physical exercise on quality of life, exercise capacity and pulmonary function in children with asthma. J Rehabil Med. 2006 Mar;38(2):130-5. https://doi.org/10.1080/16501970500476142

5. Furtado PR, Maciel ÁCC, Barbosa RRT, Silva AAM da, Freitas DA de, Mendonça KMPP de. Association between quality of life, severity of asthma, sleep disorders and exercise capacity in children with asthma: A cross-sectional study. Brazilian J Phys Ther. 2019;23(1):12-8. https://doi.org/10.1016/j.bjpt.2018.08.010.

6. Lunardi AC, da Silva CCBM, Mendes FAR, Marques AP, Stelmach R, Carvalho CRF. Musculoskeletal dysfunction and pain in adults with asthma. J Asthma. 2011;48(1):105-10. https://doi.org/10.3109/02770903.2010.520229

7. Villa F, Castro APBM, Pastorino AC, Santarém JM, Martins MA, Jacob CMA, et al. Aerobic capacity and skeletal muscle function in children with asthma. Arch Dis Child. 2011;96(6):554-9. https://doi.org/10.1136/adc.2011.212431

8. Ramos E, de Oliveira LVF, Silva AB, Costa IP, Corrêa JCF, Costa D, et al. Peripheral muscle strength and functional capacity in patients with moderate to severe asthma. Multidiscip Respir Med. 2015;10(1):3. https://doi. org/10.1186/2049-6958-10-3

9. Caspersen CJ, Powell KE, Christenson GM. Physical activity, exercise, and physical fitness: Definitions and distinctions for health-related research. Public Health Rep. 1985;100(2):126.

10. Welsh L, Roberts GDR, Kemp JG, Fitness and physical activity in children with asthma. Sports Med. 2004:34(13):861-70. https://doi.org/10.2165/00007256-200434130-00001

11. Weston AR, MacFarlane DJ, Hopkins WG. Physical activity of asthmatic and non-asthmatic children. J Asthma. 1989;26(5):279-86.

12. Kowalski KC, Crocker PRE, Faulkner RA. Validation of the physical activity questionnaire for older children. Pediatr Exerc Sci. 1997;9:174-86.

13. Counil F-P, Varray A, Karila C, Hayot M, Voisin M, Prefaut C. Wingate test performance in children with asthma: Aerobic or anaerobic limitation? Med Sci Sports Exerc. 1997;29(4):430-5. https://doi.org/10.1097/00005768-199704000-00002 
14. Vandewalle $H$, Péerès $G$, Monod $H$. Standard anaerobic exercise tests. Sport Med. 1987;4(4):268-89. https://doi. org/10.2165/00007256-198704040-00004

15. Ayalon A, Inbar O, Bar-Or O. Relationships among measurements of explosive strength and anaerobic power. In: Nelson RC, Morehouse CA, editors. International series on sport sciences. Vol. 1. Biomechanics IV. Baltimore, MD: University Park Press, 1974: 572-7.

16. Préfaut C, Varray A, Vallet G. Pathophysiological basis of exercise training in patients with chronic obstructive lung disease. Eur Respir Rev. 1995;5:27-32.

17. Bar-Or 0 . The wingate anaerobic test an update on methodology, reliability and validity. Sport Med. 1987;4(6):381-94. https://doi.org/10.2165/00007256-198704060-00001

18. Pau M, Mandaresu S, Leban B, Nussbaum MA. Short-term effects of backpack carriage on plantar pressure and gait in schoolchildren. J Electromyogr Kinesiol. 2015;25(2):406-12. https://doi.org/10.1016/j.jelekin.2014.11.006

19. Latorre-Román PÁ, Navarro-Martínez AV, Mañas-Bastidas A, García-Pinillos F. Handgrip strength test as a complementary tool in monitoring asthma in daily clinical practice in children. Iran J Allergy Asthma Immunol. 2014 Jan 1;13:404-11.

20. Grippi MA, Elias JA, Fishman JA, Kotloff RM, Pack Al, Senior RM. Pulmonary mechanics. Fishmans Pulm Dis Disord. 1998;1:149-62.

21. Saritas N, Ozkarafaki I, Pepe O, Buyukipekci S. Evaluatıon of body fat percentage of male university students according to three different method. Sağlık Bilim Der. 2011;20(2):107-15.

22. Singh SJ, Morgan MD, Scott S, Walters D, Hardman AE. Development of a shuttle walking test of disability in patients with chronic airways obstruction. Thorax. 1992 Dec 1;47(12):1019-24. https://doi.org/10.1136/thx.47.12.1019

23. Simsek S, Inal-Ince D, Cakmak A, Emiralioglu N, CalikKutukcu E, Saglam M, et al. Reduced anaerobic and aerobic performance in children with primary ciliary dyskinesia. Eur $J$ Pediatr. 2018 May;177(5):765-73. https://doi.org/10.1007/ s00431-018-3121-2

24. Leggin BG, Neuman RM, lannotti JP, Williams GR, Thompson EC. Intrarater and interrater reliability of three isometric dynamometers in assessing shoulder strength. J Shoulder Elb Surg. 1996;5(1):18-24. https://doi.org/10.1016/ S1058-2746(96)80026-7

25. Shechtman O, Gestewitz L, Kimble C. Reliability and validity of the DynEx dynamometer. J Hand Ther. 2004 Oct 1;17(4):438. https://doi.org/10.1197/j.jht.2005.04.002

26. Theodorou A, Paradisis G, Panoutsakopoulos V, SmpokosSbokos E, Skordilis E, Cooke C. Performance indices selection tor assessing anaerobic power during a 30 second vertical jump test. J Sports Med Phys Fitness. 2013;53:596-603.

27. Verran JA. Munro BH, Visintainer MA, Page EB. Statistical methods for health care research. Philadelphia: Lippincott, 1986: 381 pp. Res Nurs Health. 1987;10(6):406-8.

28. Boulet LP. Asthma and obesity. Clin Exp Allergy. 2013;43(1):821. https://doi.org/10.1111/j.1365-2222.2012.04040.x
29. Ergin E, Savci S, Kahraman BO, Tanriverdi A, Ozsoy I, Atakul G, et al. Three-axis accelerometer system for comparison of gait parameters in children with cystic fibrosis and healthy peers. Gait Post. 2020;78:60-4. https://doi.org/10.1016/j. gaitpost.2020.02.018

30. Umtawska W. Adipose tissue content and distribution in children and adolescents with bronchial asthma. Respir Med. 2015 Feb 1;109(2):200-7. https://doi.org/10.1016/j. rmed.2014.11.006

31. Deane CS, Wilkinson DJ, Phillips BE, Smith K, Etheridge T, Atherton PJ. "Nutraceuticals" in relation to human skeletal muscle and exercise. Am J Physiol Endocrinol Metab. 2017 Apr;312(4):E282-99. https://doi.org/10.1152/ajpendo.00230.2016

32. Decramer M, Lacquet LM, Fagard R, Rogiers P. Corticosteroids contribute to muscle weakness in chronic airflow obstruction. Am J Respir Crit Care Med. 1994;150(1):11-16. https://doi. org/10.1164/ajrccm.150.1.8025735

33. Souza JA, Pasinato F, Basso D, Correa ECR, da Silva AMT. Biophotogrammetry: Reliability of measurements obtained with a posture assessment software (SAPO). Rev Bras Cineantropometria Desempenho Hum. 2011;13:299-305. https://doi.org/10.1590/S1980-00372011000400009

34. Parreira VF, Janaudis-Ferreira T, Evans RA, Mathur S, Goldstein RS, Brooks D. Measurement properties of the incremental shuttle walk test: A systematic review. Chest. 2014 Jun 1;145(6):1357-69. https://doi.org/10.1378/chest.13-2071

35. Reimberg MM, Pachi JRS, Scalco RS, Serra AJ, Fernandes L, Politti F, et al. Patients with asthma have reduced functional capacity and sedentary behavior. J Pediatr (Rio J). 2020;96(1):53-59. https://doi.org/10.1016/j.jped.2018.07.011.

36. Lanza FC, Reimberg MM, Ritti-Dias R, Scalco RS, Wandalsen GF, Sole $\mathrm{D}$, et al. Validation of the modified shuttle test to predict peak oxygen uptake in youth asthma patients under regular treatment. Front Physiol. 2018;9:919. https://doi.org/10.3389/ fphys.2018.00919

37. Ram FSF, Robinson SM, Black PN. Effects of physical training in asthma: A systematic review. Br J Sports Med. 2000;34(3): 162-7. https://doi.org/10.1136/bjsm.34.3.162

38. Counil FP, Varray A, Matecki S, Beurey A, Marchal P, Voisin M, et al. Training of aerobic and anaerobic fitness in children with asthma. J Pediatr. 2003 Feb;142(2):179-84. https://doi. org/10.1067/mpd.2003.83

39. Counil FP, Karila C, Varray A, Guillaumont S, Voisin M, Préfaut C. Anaerobic fitness in children with asthma: Adaptation to maximal intermittent short exercise. Pediatr Pulmonol. 2001;31(3):198-204. https://doi.org/10.1002/ppul.1029

40. Klijn PH, Terheggen-Lagro SW, van der Ent CK, van der Net J, Kimpen JL, Helders PJ. Anaerobic exercise in pediatric cystic fibrosis. Pediatr Pulmonol. 2003;36(3):223-9. https://doi. org/10.1002/ppul.10337

41. Boas SR, Danduran MJ, Saini SK. Anaerobic exercise testing in children with asthma. J Asthma. 1998;35(6):481-7. https://doi. org/10.3109/02770909809071001 